Case Report

\section{The creative self in anorexics}

\author{
Dalmotto $\mathrm{M}^{1 *}$ and Fassino $\mathrm{S}^{2}$ \\ ${ }^{1}$ Psychiatrist, University Psychiatric Unit, Torino, Italy \\ ${ }^{2}$ Emeritus Director, University Psychiatric Unit, Torino, Italy
}

\section{Abstract}

The article describes the interaction of anorexic patients, hospitalized in the Regional Pilot Psychiatric Service for the treatment of Anorexia in the Molinette Hospital of Turin, with the reading volunteering group. On the basis of said interaction, the Creative Self is searched for in patients and shows into be present in different ways. It seems anyway enhanced by the presence in the reading group.

\section{Introduction}

For some years, thanks to an agreement with the Torino Book Club, in some hospital wards of the city, groups of reading volunteers have been operating. Particularly, in the University Pilot Service for the treatment of Anorexia, a group of volunteers to which I have belonged for about 2 years, interacts with patients once a week. Each volunteer reads pieces, poems, aphorisms, following the rule prescribing that they are not to dwell about conflictual and psychopathological subjects on the anorexic disease, for the reason that it would not be possible in such context to reelaborate them with the patients. The aim is, on the contrary, to be able to turn listening patients and talking volunteers from an entertainment group into an inclusion group. For this reason, volunteers, mainly not doctors, are sitting in the dining hall in a circle near patients, commenting freely. Moreover, roles are often switched between. As a matter of fact, it happens that some young anorexic brings some meaningful pieces or even pages from her diary or a story written by her rich of metaphors and reads them herself. Even though volunteers do not agree on the subjects in advance, among the participants a thin common thread of meaning is created, each time different, with cohesion and not splitting features. The number of participants unfortunately is not high, perhaps because in anorexics there is an inborn difficulty to express their feelings [1] and also because anorexia is sometimes associated with depression [2] and decreased interests. Moreover, group dynamics occur in anorexics with a law self-directedness who adjust to the leader girl's behavior. For these reasons many girls do not take part in the reading group or they do not intervene, but they often find a channel of self-expression, writing their thoughts in loneliness over a wooden board in the dining hall. Anorexics find it difficult to reach a mature identity and psychologic autonomy: for this reason, the self-creation is problematic.

\author{
More Information \\ *Address for Correspondence: \\ Dott.ssa Dalmotto Marinella, Via Servais 200/e/21, \\ 10146 Torino, Italy, Tel: 011725500 ; \\ Email: marinella.dalmotto@tiscali.it \\ Submitted: February 09, 2021 \\ Approved: March 02, 2021 \\ Published: March 03, 2021 \\ How to cite this article: Dalmotto M, Fassino S. \\ The creative self in anorexics. Arch Pathol Clin \\ Res. 2021; 5: 001-003. \\ DOI: 10.29328/journal.apcr.1001020
}

Copyright: @ 2021 Dalmotto M, et al. This is an open access article distributed under the Creative Commons Attribution License, which permits unrestricted use, distribution, and reproduction in any medium, provided the original work is properly cited.

Keywords: Anorexia; Creative self; Reading group

(D) Check for updates

(ه) OPEn ACCESS

The aim of this work is to find out to what degree the creative-self is found in anorexics [3], which explains and gives a meaning to their experiences such as, in this case, reading and being hospitalized and if it is stimulated by the reading group.

To this aim a selection of pieces and poems introduced by myself to the group are reported here below, and compared with the words and the sentences written by the anorexics.

\section{Case report of clinical series}

In the regional pilot Psychiatric Service for the treatment of Anorexia, ten anorexics -almost all of them teenagersare hospitalized for at least one month, and treated with a controlled dietetic therapy, psychotherapy, and pharmacological therapy. All their blood chemistry tests and hormonal values are examined and, if needed, rebalanced. In this Psychiatric Service are hospitalized always ten anorexics patients and few teenagers that aren't affected by anorexia but other mental diseases as depression or borderline personality disorder. In spite of the deep psychotherapy, the reading open group, set up two hours a week, is the only entertaining inclusion activity. The author took part in 28 reading meetings. The average participation in each meeting was $7+1$ patients, of whom $3+1$ were anorexic patients. Since in that ward the hospitalized patients without eating disorders were 5 , the participation of this kind of patients -depressed or with a borderline personality disorder- was higher than that of anorexics, probably for the abovementioned reasons. 
Among the subjects I chose to discuss with the group, there were 4 which mostly aroused interest among patients:

1. Hope

2. Fragility and resilience

3. Happiness

4. Friendship

In this abstract have been reported the pieces, poems and aphorisms I chose for each subject. Also, there have been reported the anorexics' comments made soon after the reading and the thoughts written later on the wooden board set on the dining hall side. The anorexic patients gave their consent to the reproduction. The contents are mostly connected with the pieces read before, but also spontaneous.

Hope

Readings.

Imparare a sperare (E. Borgna) [4]

Le luci stellari della speranza (E. Borgna) [4]

Anorexics' voices and thoughts

"In a rainy day, in and out, we found a four-leaf clover nothing happens by chance".

"You must never lose hope"

"Believe in hope, but above all love yourself and love life"

"No pain is useless and you never cry for nothing"

"Nothing will work unless you want it to"

"A ray of joy will reach us"

"While we get older the horizon tightens and hope decreases, we need someone to trigger it"

"I have been hospitalized again, but I am ready to start over."

Fragility and resilience

Readings.

Poesia (A. Merini) [5]

Poesia (E. Dickinson) [6]

Poesia (A. Merini) [5]

Anorexics' voices and thoughts

"Do not worry if you go down deeper: down there you can give yourself the push and rise again."

"I say enough after more than twenty years' disorder"

"I have been shut in again in this division after only two months"
"Leaving the past is easy, it is going on that is painful. So sometimes we fight to keep things as they are"

"Stop harming yourself, life is yours, do not throw it away that way, open your eyes, each of us every day has his own desert to tell"

"Why do not give me one more chance?"

"Only when you go down deeper you realize that life is one and must be lived to the best, it does not matter how many steps you can do, what really matters is going on"

"I am like the sea which crashing against the rocks always finds the force to try it"

\section{Happiness}

Readings.

Felicità raggiunta (E. Montale) [7]

La felicità (Trilussa) [8]

Anorexics' voices and thoughts

"You can find happiness even in the gloomiest moments, if only you remember to turn on the light"

"You are never too young or too old to get to know happiness"

"Remember to smile"

"You have to share happiness, because if you are alone you get sad."

"You need to search for happiness, because it is fleeting"

"Happiness is an instant, a state of balance"

\section{Friendship}

Readings.

La gaviota y el gato (Sepulveda) [9]

Aphorism (Isabel Allende)

Aphorism (Mark Twain)

Anorexics' voices and thoughts

"Healthy friends move off, do not understand other than walking with an anorexic is not a nice thing to be seen"

"Friendship is deeper than love"

"The relation of friendship, on the contrary of love, can be unbalanced at a certain time and then maybe invert"

In the medical division relations of friendships among we anorexics establish, but we try to respect the others' problems, not charging them with our own grieves. 
"Bella, Yale and Giulia fight together"

"I love a lot Marta and Sara"

"I love you girls"

"Sara and Stefania will reach the goal together"

"Ale, Maria and Silvia forever"

\section{Discussion}

The anorexics hospitalized in the Psychiatric Service, behaved in three different ways: a few like the creators of their own literary works, many of them like interlocutors upon stimulation, others like people expressing their own thoughts in loneliness writing on a wooden board. Also, in this last group, anyway, the performance can be seen by other people. The subject of hope found its feedback in the anorexics' past experiences, opposing the destructive concepts: "love yourself and life" and that of "life restricts the horizon". Hospitalization does not limit the hope of recovery. Fragility shows itself in the relapse of the disorder or only in a few cases is expressed by the pain of desperation. Often, on the contrary, after reaching the deepest point, there comes the awareness that they can do no other thing than "push themselves up and get back on top again" because the important thing, even at difficult times, is to go on" toward(s) improvement". The search for happiness, even if "fleeting", "a moment", is found in the anorexics' thoughts, though as the childish, functional aim of a perfect body. In the ward, the anorexics have their meals in a group following personalized diets prepared by a single dietitian, and can only rise from the table only when the last of them has finished. The hospitalization period, which allows a detachment from the family and from their pathological dynamics, lasts for a long time and it is often repeated. Therefore, among the girl's bonds of friendship are created which support them in facing the treatment of their disorder. As a matter of fact, they say they "fight together" and that "they will reach the aim together". Many are the words of fondness to each other, but "they try to respect the other one's problems, not charging her with her own anxieties. "The friendship relation can at certain times be unbalanced, and later perhaps invert". The true friends, in fact, tolerate each other's period of crisis. But in the reality, it does not always happen like this: "the healthy friends detach themselves, they do not understand" and the anorexics are left to face, mostly out of the ward, feelings of hollow and loneliness.

\section{Conclusion}

The anorexic patients have taken advantage in different ways of the reading group: from the lack of participation, to the lonely reflection, to the participation after being encouraged and lastly to the participation firsthand. This behavior could imply more or less serious degrees of rigidity both cognitive and emotional, of which Prof. Fassino's team recently found a psychobiological cerebral basis. Voices and thoughts express traits of omnipotence. The pieces and poems could arouse emotions acting as a transactional object without constrictions; that is enabling oneself to communicate with his own inside world and also with his own outside one even if with difficulty. This way an encouraging process [10] established itself towards the creative self, which is the function of personality referring to the way an individual lives stimuli and replies to them [3]. The creative self is essential as it results from the harmonic functioning of the different components of the self [3]. The stimulation of the creative increases self-esteem, very low in anorexics, creating a vicious circle from which creativity can emerge. In this regard an emblematic example is my portrait drawn by a hospitalized anorexic; the patient's creative self harmonizes the reality of the red of my hair and the green of my eyes in her fantasy into the picture of a fox.

\section{Acknowledgements}

Thanks to Mirella Zanini for her translation.

\section{Declarations}

We hereby declare that this work is original, not published, neither submitted to other Journals.

Copyrights are transferred to the Archives of Pathology and Clinical Research.

The anorexic patients gave their informed consent to the reproduction of their comments and the patient author of the drawing authorized the reproduction of same.

The study has been approved by the ethics committee.

\section{Appendix}

\section{References}

1. Fassino $S$, Amianto F, Daga GA, Leombruni P. Personality and psychopathology correlates of drop out in an outpatient psychiatric service. Panminerva Medica. 2007; 49: 7-15.

PubMed: https://pubmed.ncbi.nlm.nih.gov/17468728/

2. Fassino S, Amianto F, Gramaglia C, Facchini F, Daga GA. Temperament and character in eating disorders: ten years studies. Eat Weight Disord. 2004; 9: 81-90.

PubMed: https://pubmed.ncbi.nlm.nih.gov/15330074/

3. Adler A. The fundamental view of Individual Psychology. Int J Ind Psych. 1935; 1: 5-8.

4. Borgna E. Le passioni fragili. Milano: Feltrinelli. 2017.

5. Merini A. Fiore di poesia. Torino: Einaudi. 2014.

6. Dickinson E. Tutte le poesie. Milano: Mondadori. 1997.

7. Montale E. Ossi di seppia. Milano: Mondadori. 2003

8. Trilussa. Poesie scelte. Milano: Mondadori. 2011

9. Sepulveda L. Trilogia dell'amicizia. Milano: Ugo Guanda. 2012.

10. Rovera G. Transmotivazione: proposte per una strategia dell'incoraggiamento. Riv Psic Ind. 1982; 17: 28-50. 